\title{
NUT midline carcinoma in a young pregnant female: a case report
}

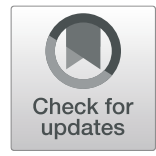

\author{
Sebastian Joel ${ }^{1^{*}}$ (D), Friederike Weschenfelder ${ }^{2}$, Ekkehard Schleussner ${ }^{2}$, Gunther O. Hofmann ${ }^{1}$ and \\ Wolfram Weschenfelder ${ }^{1}$
}

\begin{abstract}
Introduction: The NUT midline carcinoma is a rare tumor mostly reported in the midline of upper aerodigestive tract and mediastinum. Children as well as adolescents are affected without a gender distribution. A standard treatment is not established. So far, there exists no reported case of a pregnant female suffering from NUT midline carcinoma with musculoskeletal manifestation.
\end{abstract}

Case presentation: A 34-year-old woman was referred to our outpatient clinic by the general practitioner during her 31st week of pregnancy suffering from shoulder pain and dyspnea. So far, dyspnea was interpreted as a typical pregnancy-related symptom. However, a chest X-ray showed a tumor mass in the right lung in close relation to the scapula. Further examinations found metastases in different areas of the body. No pregnancy-related complications were detected by obstetric examination. After an interdisciplinary perinatal case discussion, cesarean section was directly followed by an open biopsy of the right side scapula tumor lesion. A NUT midline carcinoma was diagnosed by immunohistochemistry. Due to disseminated tumor disease in multiple non-resectable locations, a palliative systemical chemotherapy was started by the oncological outpatient clinic.

Conclusion: This report presents the case of the very rare NUT midline carcinoma under pregnancy which made interdisciplinary case discussions indispensable for therapy planning.

Keywords: NUT midline carcinoma, Pregnancy, Soft tissue tumor, Orthopedic oncology, Interdisciplinarity

\section{Introduction}

The NUT midline carcinoma is a rare tumor mostly reported in the midline of the skull, upper aerodigestive tract, and mediastinum [1-3]. Other parts of the body such as lung, abdominal organs, or bone can also be affected but cases are less common [4-6]. The first descriptions of intrathoracic high-grade carcinomas harboring the typical $(15 ; 19)$ translocation were published in 1991 by two different groups $[7,8]$. The NUT midline carcinoma affects children as well as adolescents and adults with a balanced overall gender distribution. The outcome was reported with a 2-year overall survival of $19 \%$ and a median overall

\footnotetext{
* Correspondence: sebastian.joel@med.uni-jena.de

'Department of Trauma, Hand and Reconstructive Surgery, University Hospital Jena, Jena, Germany

Full list of author information is available at the end of the article
}

survival of 6.7 months [9]. Clinical symptoms are dependent on the special location of the tumor. Patients often complain about shortness of breath, bloody sputum, non-productive cough, chest pain, nausea, odynophagia, lymphadenopathy, lumbago, local swellings, history of fever, and sweating as well as weight loss [6,10-15]. Blood tests revealed an unspecific leucocytosis [11]. So far a special blood tumor marker does not exist. After detecting a tumor mass by methods of radiological examination, usually a tumor biopsy is performed to enable a soft tissue analysis. NUT midline carcinomas are a poorly differentiated class of tumor but mostly show a typical $(15 ; 19)$ translocation in fluorescence in situ hybridization (FISH) [16]. There are several cases with cryptic translocation that do not show the typical NUT gene rearrangements by FISH [17]. As a further diagnostic test, there exists a characteristic 
monoclonal antibody to NUT genes which reaches a specificity of $100 \%$ [18]. For NUT midline carcinoma, there is no established specific therapy regimen until now. In different studies, patients received a multimodal therapy consisting of various combinations of surgery, chemotherapy, and radiotherapy [19]. Different outcomes and survival were reported because the chosen therapy regimen always depends on individual factors [19-21]. The use of BET (bromodomain and extra-terminal) protein inhibitors is a new targeting immunotherapy. It is applied alone or in combination with other therapeutic agents in patients with NUT midline carcinoma and an arrest of growth under this therapy has been reported [22].

\section{Case presentation}

A 34-year-old woman was referred to our outpatient clinic during her 31st week of pregnancy suffering from shoulder pain of the right side after lifting her 11-month-old first born. During the first pregnancy, one and a half year ago she started noticing dyspnea which was still present at the time of her presentation in our clinic. At that time, this symptom was considered as pregnancy-related therefore no special examination was arranged. Several months later the patient became pregnant again. She was still reporting of dyspnea especially at physical activity and new symptoms, cough and hemoptysis, had appeared. Due to persistent symptoms, the general practitioner arranged a chest X-ray that showed a tumor mass in the right lung in close relation to the scapula (Fig. 1).

Clinical examination showed a patient in good general health. There was a local swelling at the medial border of the right scapula with dull pressure pain. The movement of the shoulder was painless at full range of motion and strength. The auscultation of the lung presented a vesicular respiratory sound which was slightly attenuated at the right side. The patient did not suffer from pain. Family anamnesis revealed a breast cancer of the patient's mother and a bronchial carcinoma of the father. B symptoms were not reported.

The case was primarily presented to the department of obstetrics in 31 4/7 weeks of gestation. Ultrasound showed a large for gestational fetus ( $2205 \mathrm{~g}$, 93rd percentile) with normal amniotic fluid and normal feto-placental perfusion of a 34-year-old gravida 2 para 1 (one spontaneous delivery 1 year ago) with no pregnancy-related complications. A diaplacental cancer cell transmission seemed unlikely for the type of expected tumor.

MRI scans (magnetic resonance imaging, Fig. 2) of the cranium and the thorax were performed and revealed several highly suspicious lesions in the right lung, the mediastinum, the inferior angle of the right scapula with soft tissue component, and an osteolytic lesion of the 3rd thoracic vertebral body with affection of dura and spinal nerve.

An interdisciplinary perinatal case discussion with obstetricians, neonatologists, oncologists, and our orthopedic

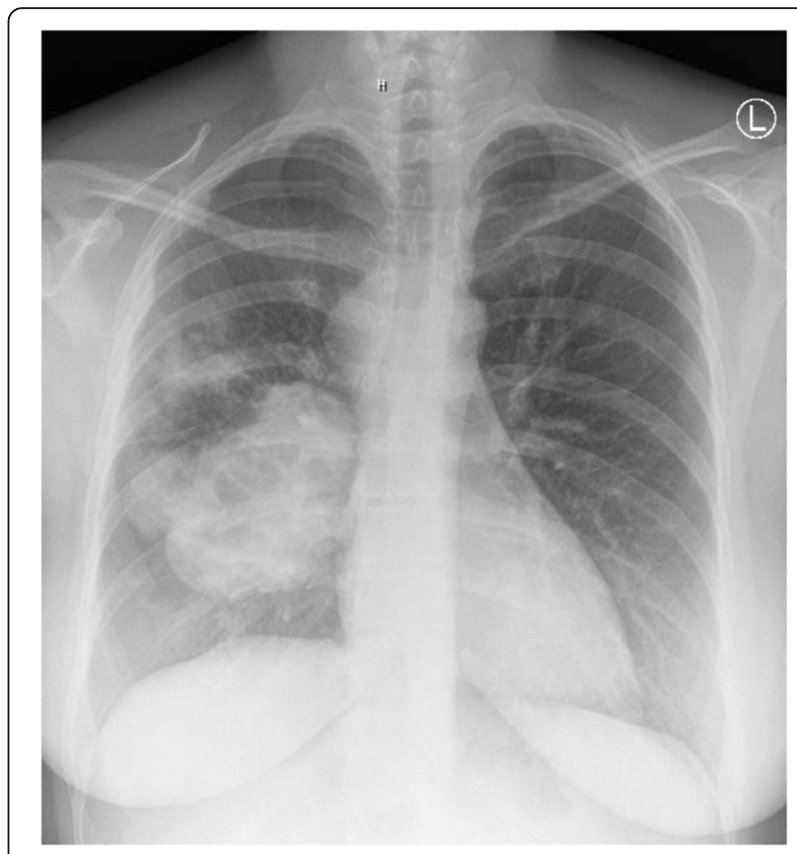

Fig. 1 X-ray AP view of thorax showing tumor mass in the right lung

department was initiated near-term discussing the conflict of delaying maternal tumor therapy and causing an iatrogenic preterm birth and its possible neonatal complications. In 32 0/7 weeks of gestation, the pros and cons due to a delivery before $340 / 7$ weeks of gestation were discussed and presented to the patient and her husband by the treating specialist, so that informed consent could be obtained. In summary, a one-stage procedure, combining the primary cesarean section and the open biopsy of the right side scapula tumor lesion was planned for $334 / 7$ weeks of gestation. Before the planned delivery, antenatal corticosteroid treatment for accelerating fetal lung maturation was implemented to minimize the risk for respiratory neonatal complications. Thrombosis and pneumonia prophylaxis were recommended due to the high-risk situation.

A fine-needle biopsy of the pulmonary tumor mass was done by bronchoscopy. Subsequently, the cesarean section was directly followed by an open biopsy of the right side scapula tumor lesion. A NUT midline carcinoma was diagnosed by immunohistochemistry (Table 1) while FISH analysis did not show the typical NUT gene rearrangements due to cryptic translocation.

The examination of the placenta did not show any signs of malignancy. After the cesarean section, a PET-CT (positron emission tomography-computed tomography, Fig. 3) was performed showing further multiple metastases in both mammae in addition to the known tumor lesions. The case was presented in a multidisciplinary tumor board. Due to disseminated tumor disease in multiple non-resectable locations, a palliative systemical chemotherapy with nab-paclitaxel $(100$ $\mathrm{mg} / \mathrm{m}^{2}$ )/carboplatin (AUC 6) was started by the oncological 

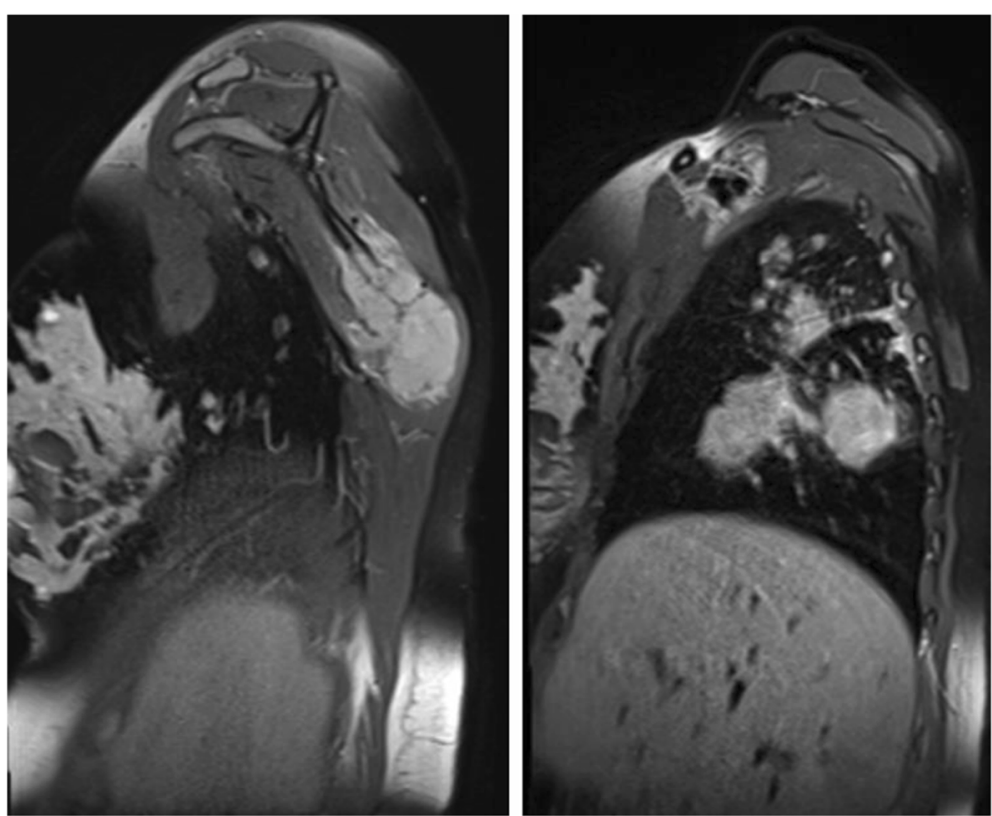

Fig. 2 MRI sagittal view showing highly suspicious lesions in the right scapula and lung

outpatient clinic (Fig. 4). Priorly, Trenantone $130 \mathrm{mg}$ subcutaneously for ovary protection was administered. Furthermore, an osteoprotective bisphosphonate therapy with Zometa $^{\circ} \mathrm{mg}$ was begun. Regarding the bone metastases in the right scapula and in the 3rd thoracic vertebral body, no surgical intervention but radiotherapy was planned in the further course as part of the palliative therapy regimen. After five courses of systemical chemotherapy with nab-paclitaxel/carboplatin, the patient showed a decline of dyspnea. A PET-CT 3 months after the start of therapy demonstrated a partial remission of known metastases in the right lung and in both mammae. Systemical chemotherapy was continued by the oncological outpatient clinic. However, the scheduled PET-CT after 5 months showed a tumor progress with growth of known metastases and new lesions in the spine and pelvis. Again, the case was discussed in multidisciplinary tumor board and systemic treatment was changed to pembrolizumab while an indication for BET inhibitors was proved in cooperation with an external oncological clinic. Unfortunately, further progress of known metastases was demonstrated radiologically as well as new spinal and pelvic lesions. After that, the patient was lost for further followup and missed further appointments.

Table 1 Biopsy of pulmonary tumor and scapula tumor lesion Immunohistochemistry NUT+, p63+

CK20-, CDX2-, GATA3-, ER-, PR-, PD-L1-, CK5/6-, ALK-, ROS1-, PAX8-, S100-, Napsin -, Melan A-, P40- (mostly), HER2 score 2+

+ positive, - negative

\section{Discussion and conclusions}

Until now NUT midline carcinomas have been reported in children and adolescents as well as adults [9]. Young women around the age of 30 may be affected by this malignancy $[15,23]$. However, this report presents the first published case of a NUT midline carcinoma in a nonsmoking young female patient under pregnancy. In the recently published review of Dalmartello et al., the most common pregnancy-associated carcinomas were melanoma, breast cancer, cervical cancer, and thyroid cancer [24]. The placenta and tumor microenvironment seems
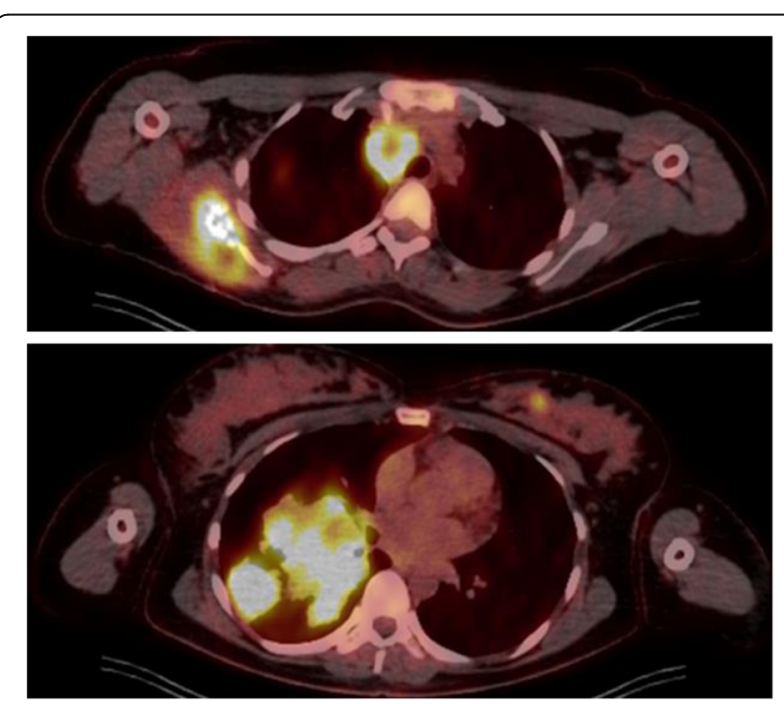

Fig. 3 PET-CT axial view showing tumor lesions in the right scapula, mediastinum, and lung 


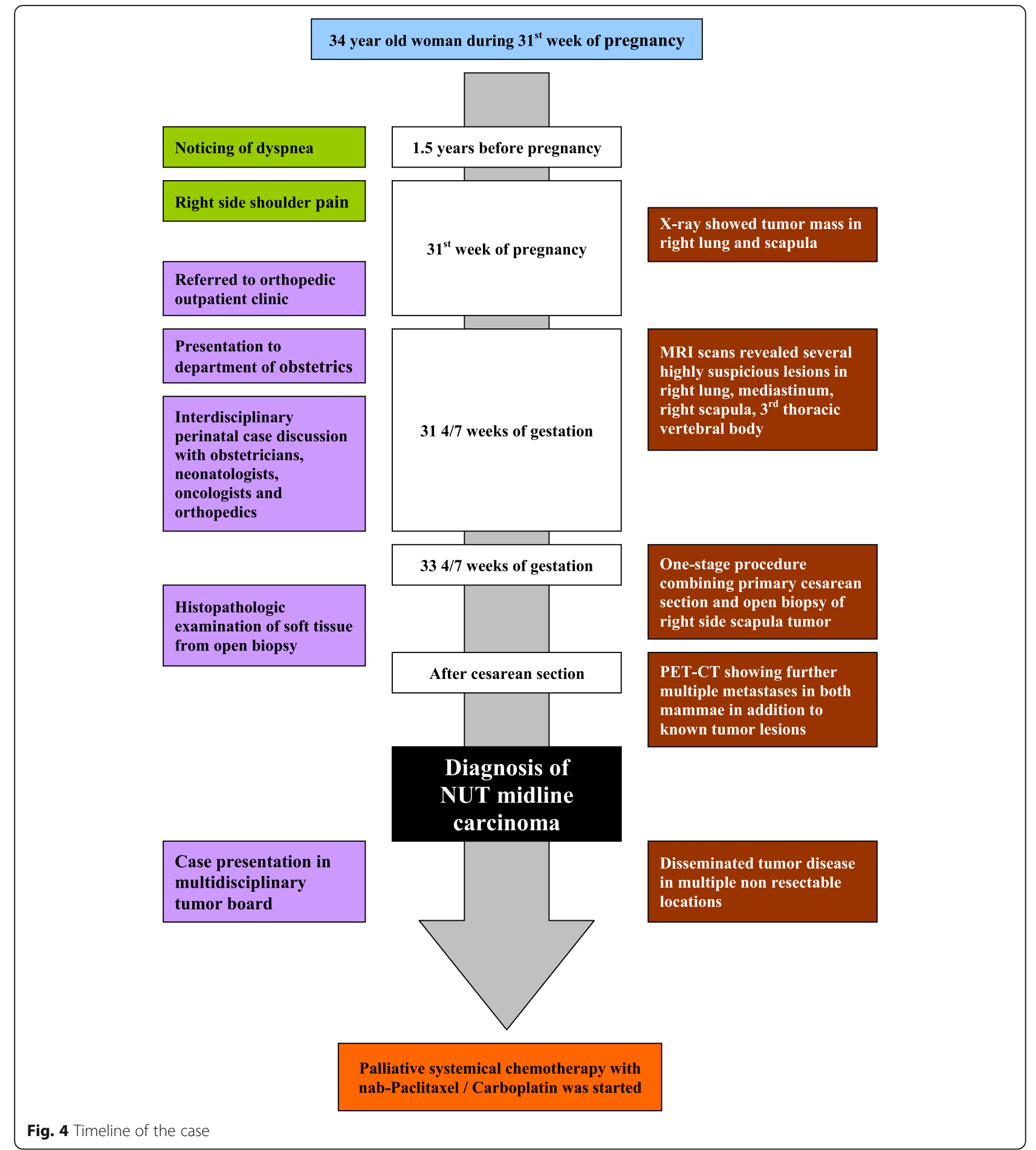

to be extremely comparable, in particular, the immune responses for growth and vascularization as well as hormone sensitivity. Beaman et al. state the importance of leucocytes in activating and supporting tumor and placental cell growth through the production of growth factors and angiogenic factors [25]. For pregnancy-associated melanoma, even diaplacental transmission has been described and therefore careful examination of placentas of women with known or suspected metastatic melanoma is recommended [26].

The patient in this case had complained of dyspnea since her first pregnancy. In addition cough and hemoptysis had occurred as further symptoms during her second pregnancy. Dyspnea is a disorder often reported by pregnant 
women. Its persistence after labor is untypical and should have led to earlier diagnostic investigations. The symptoms reported by the patient, dyspnea, cough, and hemoptysis, are typical for severe illnesses of the lung and hence for a pulmonary manifestation of a NUT midline carcinoma. In addition, the patient had noted an unclear swelling of the soft tissues below the scapula over several weeks - a condition that is a typical clinical presentation of soft tissue tumors and has to be further verified by sonography and MRI.

In published cases of NUT midline carcinomas, the primary tumor localization was mostly common in the upper aerodigestive tract and mediastinum $[1,2]$ but the lung was also reported [15]. However, the primary localization in the presented case remains unclear. According to other publications, complete surgical resection is associated with improved overall survival [19]. This could not be performed in the presented case due to the diffuse metastatic disease. Considering that there exists no standard treatment for NUT midline carcinoma until now [5, 27], the case was discussed interdisciplinary. A palliative systemical chemotherapy was started with nab-paclitaxel and carboplatin. This therapy is the first-line treatment of non-small cell lung cancer (NSCLC) in patients who are not candidates for curative surgery and/or radiation therapy [28].

In the presented case, the diagnosis and treatment of the tumor was complicated and delayed by the pregnancy of the patient. At the time the imaging of the thorax by MRI indicated a malignant disease with synchronic metastasis, the patient was in 31 4/7 weeks of gestation. Definite histological confirmation was achieved by bronchoscopic biopsy and the case then discussed interdisciplinary. The delay in further diagnostics with radiation exposure and cancer treatment of 3 weeks allowed the maturation of the fetal lung and was considered more beneficial in the palliative setting than an immediate cesarean section.

The pathological features of the tumor are also important for therapy. The NUT midline carcinoma in this case did not show the typical $(15 ; 19)$ translocation in fluorescence in situ hybridization (FISH) [16]. A monoclonal antibody to NUT genes was necessary to diagnose [18]. In these cases of a cryptic translocation, it is easy to miss a NUT midline carcinoma. This has already been reported in the case of a 13-year-old girl [29] as well as for a 28-year-old male with a misdiagnosed germ cell tumor [30]. Detailed pathological examination is important because a NUT midline carcinoma is mostly not suspected.

This report presents the case of a rare NUT midline carcinoma as tumor entity and emphasizes the need of interdisciplinary case discussions. Especially the additional factor of a pregnancy under this rare malignancy without specific therapy regimen until now had to be considered and required a highly personalized diagnostics and treatment planning. The case also illustrates that persistent or atypical symptoms should always be taken seriously and lead to supplementary diagnostics to exclude severe diagnoses.

\section{Abbreviations}

BET: Bromodomain and extra-terminal; MRI: Magnetic resonance imaging; PET-CT: Positron emission tomography-computed tomography

\section{Acknowledgements \\ The authors thank the patient and her family who generously agreed to be interviewed for this research.}

\section{CARE guidelines}

The authors ensure that the manuscript reporting adheres to CARE guidelines for case reports.

\section{Authors' contributions}

SJ and WW conceptualized and designed the study, drafted the initial manuscript. FW and ES were the obstetricians treating the patient and therefore put together the obstetric part of the course of the disease for the final manuscript. GH coordinated and supervised data collection, critically reviewed and revised the manuscript for important intellectual content. All authors approved the final manuscript as submitted and agree to be accountable for all aspects of the work.

\section{Funding}

There is no funding source. Open Access funding enabled and organized by Projekt DEAL.

Availability of data and materials

Data will be available upon request to the first author Sebastian Joel.

Ethics approval and consent to participate

Not applicable.

\section{Consent for publication}

Written informed consent for publication of their clinical details and clinical images was obtained from the patient.

\section{Competing interests}

The authors declare that they have no competing interests.

\section{Author details}

${ }^{1}$ Department of Trauma, Hand and Reconstructive Surgery, University Hospital Jena, Jena, Germany. ${ }^{2}$ Department of Obstetrics, University Hospital Jena, Jena, Germany.

Received: 20 August 2020 Accepted: 26 October 2020

Published online: 07 November 2020

\section{References}

1. Stelow EB, French CA. Carcinomas of the upper aerodigestive tract with rearrangement of the nuclear protein of the testis (NUT) gene (NUT midline carcinomas). Adv Anatomic Pathol. 2009;16(2):92-6. https://doi.org/10.1097/ PAP.0b013e31819923e4.

2. Bishop JA, Westra WH. NUT midline carcinomas of the sinonasal tract. Am J Surg Pathol. 2012;36(8):1216-21. https://doi.org/10.1097/PAS. Ob013e318254ce54

3. Stelow EB, Bishop JA. Update from the 4th edition of the World Health Organization classification of head and neck tumours: tumors of the nasal cavity, paranasal sinuses and skull base. Head Neck Pathol. 2017;11(1):3-15 https://doi.org/10.1007/s12105-017-0791-4.

4. Shehata BM, Steelman CK, Abramowsky CR, Olson TA, French CA, Saxe DF, Ricketts RR, Katzenstein HM. NUT midline carcinoma in a newborn with multiorgan disseminated tumor and a 2-year-old with a pancreatic/hepatic primary. Pediatric Dev Pathol. 2010;13(6):481-5. https://doi.org/10.2350/0910-0727-CR. 1 
5. Cao J, Chen D, Yang F, Yao J, Zhu W, Zhao C. NUT midline carcinoma as a primary lung tumor: a case report. J Thoracic Dis. 2017;9(12):E1045-9. https://doi.org/10.21037/jtd.2017.11.50.

6. Harms A, Herpel E, Pfarr N, Penzel R, Heussel CP, Herth FJ, Dienemann H Weichert W, Warth A. NUT carcinoma of the thorax: case report and review of the literature. Lung Cancer. 2015;90(3):484-91. https://doi.org/10.1016/j. lungcan.2015.10.001.

7. Kees UR, Mulcahy MT, Willoughby ML. Intrathoracic carcinoma in an 11year-old girl showing a translocation t(15;19). Am J Pediatric Hematol Oncol. 1991;13(4):459-64.

8. Kubonishi I, Takehara N, Iwata J, Sonobe H, Ohtsuki Y, Abe T, Miyoshi I. Novel t(15;19)(q15;p13) chromosome abnormality in a thymic carcinoma. Cancer Res. 1991;51(12):3327-8.

9. Bauer DE, Mitchell CM, Strait KM, Lathan CS, Stelow EB, Luer SC, Muhammed S, Evans AG, Sholl LM, Rosai J, Giraldi E, Oakley RP, RodriguezGalindo C, London WB, Sallan SE, Bradner JE, French CA. Clinicopathologic features and long-term outcomes of NUT midline carcinoma. Clin Cancer Res. 2012;18(20):5773-9. https://doi.org/10.1158/1078-0432.CCR-12-1153.

10. Agaimy A, Fonseca I, Martins C, Thway K, Barrette R, Harrington K, Hartmann A, French CA, Fisher C. NUT carcinoma of the salivary glands: clinicopathologic and molecular analysis of 3 cases and a survey of NUT expression in salivary gland carcinomas. Am J Surg Pathol. 2018:42(7):87784. https://doi.org/10.1097/PAS.0000000000001046.

11. Reddy R, Woods TR, Allan RW, Malhotra P, Mehta HJ, Sarkar PK, Boyce BJ, Asirvatham JR. NUT (nuclear protein in testis) carcinoma: a report of 2 cases with different histopathologic features. Int J Surg Pathol. 2018; 1066896918796606. https://doi.org/10.1177/1066896918796606.

12. Nakamura H, Tsuta K, Tsuda H, Katsuya Y, Naka G, lizuka T, Igari T. NUT midline carcinoma of the mediastinum showing two types of poorly differentiated tumor cells: a case report and a literature review. Pathol Res Pract. 2015;211(1):92-8. https://doi.org/10.1016/j.prp.2014.07.006.

13. Maher OM, Christensen AM, Yedururi S, Bell D, Tarek N. Histone deacetylase inhibitor for NUT midline carcinoma. Pediatric Blood Cancer. 2015;62(4):7157. https://doi.org/10.1002/pbc.25350.

14. Engleson J, Soller M, Panagopoulos I, Dahlen A, Dictor M, Jerkeman M. Midline carcinoma with $\mathrm{t}(15 ; 19)$ and BRD4-NUT fusion oncogene in a 30year-old female with response to docetaxel and radiotherapy. BMC Cancer. 2006;6:69. https://doi.org/10.1186/1471-2407-6-69.

15. Sholl LM, Nishino M, Pokharel S, Mino-Kenudson M, French CA, Janne PA, Lathan C. Primary pulmonary NUT midline carcinoma: clinical, radiographic, and pathologic characterizations. J Thoracic Oncol. 2015;10(6):951-9. https:// doi.org/10.1097/JTO.0000000000000545.

16. French CA. Pathogenesis of NUT midline carcinoma. Ann Rev Pathol. 2012;7: 247-65. https://doi.org/10.1146/annurev-pathol-011811-132438.

17. Fang W, French CA, Cameron MJ, Han YD, Liu HG. Utility of NUT gene expression and rearrangement in diagnosis of NUT midline carcinoma in upper respiratory tract. Zhonghua Bing Li Xue Za Zhi. 2012;41(8):519-24. https://doi.org/10.3760/cma.j.issn.0529-5807.2012.08.003.

18. Haack H, Johnson LA, Fry CJ, Crosby K, Polakiewicz RD, Stelow EB, Hong SM, Schwartz BE, Cameron MJ, Rubin MA, Chang MC, Aster JC, French CA. Diagnosis of NUT midline carcinoma using a NUT-specific monoclona antibody. Am J Surg Pathol. 2009:33(7):984-91. https://doi.org/10.1097/PAS. Ob013e318198d666.

19. Chau NG, Hurwitz S, Mitchell CM, Aserlind A, Grunfeld N, Kaplan L, Hsi P, Bauer DE, Lathan CS, Rodriguez-Galindo C, Tishler RB, Haddad RI, Sallan SE, Bradner JE, French CA. Intensive treatment and survival outcomes in NUT midline carcinoma of the head and neck. Cancer. 2016;122(23):3632-40. https://doi.org/10.1002/cncr.30242.

20. Lemelle L, Pierron G, Freneaux P, Huybrechts S, Spiegel A, Plantaz D, Julieron M, Dumoucel S, Italiano A, Millot F, Le Tourneau C, Leverger G, Chastagner P, Carton M, Orbach D. NUT carcinoma in children and adults: a multicenter retrospective study. Pediatric Blood Cancer. 2017;64(12). https://doi.org/10.1002/pbc.26693.

21. Giridhar P, Mallick S, Kashyap L, Rath GK. Patterns of care and impact of prognostic factors in the outcome of NUT midline carcinoma: a systematic review and individual patient data analysis of 119 cases. Eur Arch Otorhinolaryngol. 2018;275(3):815-21. https://doi.org/10.1007/s00405-018-4882-y.

22. Stathis A, Zucca E, Bekradda M, Gomez-Roca C, Delord JP, de La Motte RT, Uro-Coste E, de Braud F, Pelosi G, French CA. Clinical response of carcinomas harboring the BRD4-NUT oncoprotein to the targeted bromodomain inhibitor OTX015/MK-8628. Cancer Discov. 2016;6(5):492-500. https://doi.org/10.1158/2159-8290.CD-15-1335.

23. Kuroda S, Suzuki S, Kurita A, Muraki M, Aoshima Y, Tanioka F, Sugimura H. Cytological features of a variant NUT midline carcinoma of the lung harboring the NSD3-NUT fusion gene: a case report and literature review. Case Rep Pathol. 2015;2015:572951. https://doi.org/10.1155/2015/572951.

24. Dalmartello M, Negri E, La Vecchia C, Scarfone G, Buonomo B, Peccatori FA, Parazzini F. Frequency of pregnancy-associated cancer: a systematic review of population-based studies. Cancers. 2020;12(6). https://doi.org/10.3390/ cancers12061356.

25. Beaman KD, Dambaeva S, Katara GK, Kulshrestha A, Gilman-Sachs A. The immune response in pregnancy and in cancer is active and supportive of placental and tumor cell growth not their destruction. Gynecol Oncol. 2017; 145(3):476-80. https://doi.org/10.1016/j.ygyno.2017.04.019.

26. Alexander A, Samlowski WE, Grossman D, Bruggers CS, Harris RM, Zone Jj, Noyes RD, Bowen GM, Leachman SA. Metastatic melanoma in pregnancy: risk of transplacental metastases in the infant. J Clin Oncol. 2003;21(11): 2179-86. https://doi.org/10.1200/JCO.2003.12.149.

27. Tan E, Mody MD, Saba NF. Systemic therapy in non-conventional cancers of the larynx. Oral Oncol. 2018;82:61-8. https://doi.org/10.1016/j.oraloncology. 2018.05.005.

28. Blair HA, Deeks ED. Albumin-bound paclitaxel: a review in non-small cell lung cancer. Drugs. 2015;75(17):2017-24. https://doi.org/10.1007/s40265015-0484-9.

29. Puliyel MM, Mascarenhas L, Zhou S, Sapra A, Dal Cin P, French CA, Venkatramani R. Nuclear protein in testis midline carcinoma misdiagnosed as adamantinoma. J Clin Oncol. 2014;32(15):e57-60. https://doi.org/10.1200/ JCO.2012.48.5300.

30. Harada Y, Koyama T, Takeuchi K, Shoji K, Hoshi K, Oyama Y. NUT midline carcinoma mimicking a germ cell tumor: a case report. BMC Cancer. 2016; 16(1):895. https://doi.org/10.1186/s12885-016-2944-3.

\section{Publisher's Note}

Springer Nature remains neutral with regard to jurisdictional claims in published maps and institutional affiliations.
Ready to submit your research? Choose BMC and benefit from:
- fast, convenient online submission
- thorough peer review by experienced researchers in your field
- rapid publication on acceptance
- support for research data, including large and complex data types
- gold Open Access which fosters wider collaboration and increased citations
- maximum visibility for your research: over $100 \mathrm{M}$ website views per year
At BMC, research is always in progress.
Learn more biomedcentral.com/submissions 